\title{
On the dynamic commodity price pass-through effect to CPI constituents
}

\section{Stephan Unger ( $\nabla$ sunger@anselm.edu )}

Saint Anselm College https://orcid.org/0000-0003-4499-402X

\section{Goekhan Cebiroglu}

University of Vienna

\section{Research}

Keywords: Commodities, price pass-through, CPI, inflation, price dynamics

Posted Date: February 15th, 2020

DOI: https://doi.org/10.21203/rs.2.23157/v1

License: (c) (i) This work is licensed under a Creative Commons Attribution 4.0 International License. Read Full License 


\title{
On the dynamic commodity price pass-through effect to CPI constituents
}

\author{
Gökhan Cebiroğlu ${ }^{1}$ and Stephan Unger*2 \\ ${ }^{1}$ Credit Suisse, 1 Cabot Square, Canary Wharf, London E14 4QJ, UK, email: \\ goekhan.cebi@gmail.com \\ 2 Saint Anselm College, Department of Economics \& Business, Saint Anselm Drive \\ 100, Manchester, NH, USA, email: sunger@anselm.edu \\ *Corresponding author
}

February, 2020

\begin{abstract}
This paper analyzes the price pass-through effect of the most heavily traded commodities to CPI constituents. We reveal the differences between EU CPI and US CPI constituent dependency on commodity prices, and investigate the dynamics of the price pass-through effect. Our major finding is that due to globalization the US exhibits a high degree of de-industrialization indicated by a break down of the commodity price pass-through effect, while European consumer prices still exhibit a significant exposure to commodity price fluctuations.
\end{abstract}

Keywords: Commodities, price pass-through, CPI, inflation, price dynamics.

\section{Introduction}

Price inflation of goods and services is determined by money- and real goods supply- and demand, as well as commodity prices. Commodity prices themselves are again a function of supply and demand by industry and individuals. The degree up to which price changes in commodities affect consumer prices is called the pass-through effect.

Various price pass-through effects have already been studied, while most of the literate deals with the pass-through effect of exchange rate changes to consumer prices, e.g. Campa and Goldberg (2005) find evidence for a short as well as long term transmission of exchange rate changes to import prices. McCarthy (2007) 
studies the pass-through of exchange rates and import prices to domestic inflation in industrialized economies and exchange rate and finds that exchange rate shocks have modest effects on domestic inflation, while import price shocks appear to have a larger effect. Pass-through appears to be larger in countries with a higher import share of domestic demand as well as in countries with more persistent exchange rates and import prices. He further stresses that role of exchange rate and import price shocks in explaining consumer price fluctuations is relatively modest. A number of studies on the pass-through to CPI prices have been conducted by Woo (1984), Feinberg (1986) Feinberg (1989), and Parsley and Popper (1998).

Pass-through effects of commodities to consumer prices were not analyzed extensively in literature so far, but some examples with indicating results may be mentioned here: E.g. Marazzi et al. (2005) studied the exchange rate pass-through to U.S. import prices and find evidence for a decline in exchange rate pass-through to U.S. import prices over the past decades. Their work indicates that an increasing share of exchange rate pass-through has occurred through the commodity-price channel in recent years, which indicates a decrease in the pure commodity price pass-through share. One reason for the decreasing share of commodity price through effect may be attributed to the globalization, as the share of (commodity-intensive) industrial supplies in U.S. imports was reduced over time, while the presence of Chinese exporters in U.S. markets increased. Blomberg and Harris (1995) examine the empirical relationship between commodity prices and consumer price inflation, and find that "...commodities' reputation as a useful leading indicator of inflation is actually based more on fable than fact. " By testing eight commonly used indexes, they conclude that although commodities had some predictive power in the past, the commodity-consumer price connection has broken down over the past decades. As a possible reason they argue with a diminished role of traditional commodities in U.S. production and the "sterilization" of some inflation signals by offsetting monetary policy actions.

The effect of globalization on trade, import, export, etc. has been studied mostly by central banks, but the amount of research about the effect of globalization on inflation in is still scarce. Engel (2013) examines some standard open-economy New Keynesian models to address the question of how globalization affects the inflation process and finds that openness matters for inflation because the foreign output gap influences domestic inflation, and potentially also because exchange rates affect aggregate demand through wealth effects

Our research yields at explaining the CPI changes on a granular level, namely on the level of its aggregated constituents. Since all CPI constituents originate from some sort of commodity, it appears natural to raise the questions by how much which commodity affects which aggregated constituent within which time frame. That's exactly the question we are trying to answer by conducting a VAR between the most 
important and heavily traded commodities and each aggregated CPI constituent, and analyzing its pass-through effect over time.

Our contribution to the existing literature is the novel investigation of the difference between the price pass through-effects to European and US CPI aggregated constituents, and to analyze the dynamics behind that. To the best of our knowledge we are the first who break down the instantaneous as well as lagged price pass-through effect with respect to the difference in aggregated EU CPI and US CPI constituents. The implications hinge from production, import/export policies, to monetary policy determination since the price levels of a country depend heavily on the underlying commodity prices.

Why is it important to understand the granular effect of commodity prices changes on aggregated CPI constituents? First of all, the CPI is subject to re-evaluation of its ingredients and weight allocations every 2 years. ${ }^{1}$ By understanding the instantaneous as well as lagged pass-through effect, one can deduct various insights from the dynamics of changes in the basket constituencies.

Secondly, understanding the pass-through effect enables to understand possible supply and demand gluts or shortages of complements or substitutes.

Third, by looking at the different effects, globalization has had on Europe and US, it is possible to identify not only cultural and consumer behavior differences, but also how changes in commodity prices affect these, since changes in consumer prices might change the culture and consumer behavior of a country's citizens. Kohn (2006) addressed already 2006 in his speech that "...Although inflation is ultimately a monetary phenomenon, it seems natural to expect, as others have argued, that these developments would have exerted some downward pressure on inflation in the United Stat...", which reflects the diminished effect, globalization has on the pass-through effect of commodities to consumer prices.

Papademos (2007) remarked in 2007 in a speech that "...steadily rising integration could potentially lead to steadily falling unit labour costs and, ceteris paribus, to protracted periods of lower inflation."

Rigobon (2008) analyzes the commodity pass-through effect on CPI item prices for Latin American countries by running single regressions over a few depicted CPI items. He finds that wheat has an even greater impact on the economy than oil. However, in this paper we also take care of feedback effects among the CPI con-

\footnotetext{
${ }^{1}$ The weights for CPI-U and CPI-W are held constant for 24 months, changing in January of even-numbered years. The weights for C-CPI-U are updated each month to reflecting changes in consumption patterns in the last month. Thus, if people on average eat more chicken and less beef or more apples and fewer oranges than the previous month, that change would be reflected in next month's C-CPI-U. However, it would not be reflected in CPI-U and CPI-W until January of the next even-numbered year Bureau of Labor Statistics (2013)
} 
stituents by conducting VARs, compare the effect on the EU and US economy, and draw conclusions regarding cultural and economic implications of globalization on these economies. By analyzing the different pass-through effects in Europe and the US we are able to identify the anatomy of the economic structure of both economies.

We will first give an overview of the data we use, as well as on the methodology, explaining the conducted VAR ought to capture the dynamics as well as the granular impact of commodity price changes on the aggregated CPI constituents in the US as well as in Europe. We then present the results and conclude in the final section.

\section{Data and methodology}

We use monthly data of the eleven most important or heavily traded commodities worldwide, from Jan 30, 1998 until Sept 29, 2018. The commodity futures we use are WTI oil, natural gas, wool, cotton, sugar, copper, coffee, cattle, aluminium, gold, and silver. For the EU CPI we use the following 12 corresponding aggregated constituents for the same time period and frequency: Food and non-alcoholic beverages; Alcoholic beverages; Clothing and Footweare; Housing, Water, Electricity, Gas and other Fuels; Furnishing, Household equipment and Maintenance; Health; Transport; Communications; Recreation and Culture; Education; Restaurants and Hotels; Miscellaneous Goods and Services.

For the US CPI we use the following corresponding 10 aggregated constituents: Food and beverages; Alcoholic beverages; Housing; Apparel; Transport; Medical care; Recreation; Education; Communication; Other goods and services.

In order to determine the lagged impact of commodity and CPI aggregated constituent levels we employ a vector autoregressive (VAR) framework (see Engle (2001)). VAR is particularly suited to capture dynamic and lagged cross-interactions between the variable of interests. Therefore, the vector autoregressive model has the form

$$
y_{t}=A_{1} y_{t-1}+A_{2} y_{t-2}+\ldots+A_{i} y_{t-k}+u_{t}
$$

with $y_{t}$ representing the $(2 \times 1)$ endogenous vector $y_{t}=\left(r_{t}^{p}, r_{t}^{v}\right)$ and $A_{i}$ denoting $(2 \times 2)$ coefficient matrices for $i=1, \ldots, k$ and $u_{t}$ denoting the vector of zero mean white noise error terms with $\mathbb{E}\left[u_{t} u_{t}^{\prime}\right]=\Sigma_{u}$.

To assess the dynamic linkage between endogenous components, it is helpful to switch to the corresponding moving average representation of (1) (Lütkepohl $(2006))$, i.e.,

$$
y_{t+n}=\sum_{i=0}^{\infty} \Phi_{i} u_{t+n-i}
$$

with $\Phi_{0}=I_{2}$ and $\Phi_{s}=\sum_{j=1}^{k} \Phi_{s-j}$ for $s>0$. The matrices $\Phi_{i}$ represent the VAR model's impulse response functions. They represent the response of one variable due 
to a shock or innovation in another variable. Or more formally,

$$
\left\{\Phi_{n}\right\}_{i, j}=\frac{\partial y_{i, t+n}}{\partial \epsilon_{j, t}}
$$

they represent the elasticities or multiplies of one variable with respect to another at individual lags. ${ }^{2}$ Therefore, the impulse response functions are well equipped to provide structural evidence on causality between two variables.

Notice that the matrices $\Phi_{i}$ only provide evidence of local responses pertaining to the specific lag in time. To assess the cumulative impact of changes from one variable on a different variable, it is warranted to work with the cumulative impulse response functions instead, i.e.,

$$
\left\{\Xi_{n}\right\}_{i, j}=\sum_{l=1}^{n}\left\{\Phi_{n}\right\}_{i, j} .
$$

From now on, to assess the aggregate or total impact, we consider the properties of the cross-terms $\left\{\Psi_{i}\right\}_{12}$ and $\left\{\Psi_{i}\right\}_{21}$. Thus, the framework easily allows to capture asymmetric bi-directional causal links.

To ease illustration, we henceforth use the notation

$$
\Psi_{c \rightarrow p} \equiv\{\Psi\}_{21}, \quad \Psi_{p \rightarrow v} \equiv\{\Psi\}_{12},
$$

where $\Psi_{v \rightarrow p}$ denotes the (cumulative) impulse response of changes in Commodity prices $(c)$ on changes in aggregated CPI constituent prices $(p)$ and vice versa.

We conduct the estimation procedure for time lags of 30 months.

\section{Results}

The first major finding is that the difference in strength of the commodity price pass-through effect to its aggregated CPI constituents between EU and US is significant. The EU exhibits a much higher pass-through effect than the US, as it is much more sensitive in terms of magnitude and time length of lasting price changes in commodities. The reason for the increased insensitivity of US consumer prices to commodity price fluctuations is the degree at which the US has outsourced production in comparison to the EU.

The second major finding is that across all commodities, transportation is the most affected CPI constituent among all the others. The reason for this effect might lie in the fact that transport related constituents are at most exposed to all commodities in its value added chain compared to its other CPI constituents.

\footnotetext{
${ }^{2}$ The brace notation is used to refer to matrix entries and the subscripts refer to the indices of the respective matrix entry.
} 
The impulse response functions reveal some interesting differences in the commodity price pass-through effects between EU and US economic structure, consumer behavior and production structure.

\section{1. $E U$}

Aluminium: The positive effect on transportation and housing indicates that a price increase in aluminium causes a price surge in construction of houses as well as in all transportation related items, such as vehicle parts, etc. with a time lag of one year. The effect is remaining for housing, while fading after a year for transportation.

Copper: A lasting positive impact on education indicates the dependency and heavy usages of this commodity by various industries, while the negative effect of copper price changes on housing and communications shows that the industries are looking for substitutes in case copper gets more expensive. Transportation and alcoholic beverages are just positively affected for a year, after that the effect fades.

Gold: Gold has a sharply negative and long lasting effect on transportation, housing and food. Since an increase in gold price indicates uncertainty in financial conditions, such as in credit supply and equity prices, it shows a decrease in demand for other constituents.

Silver: Silver exhibits a lasting negative impact on transportation, communication, furnishings,and health and housing, while having a positive impact on education. The wide spread impacts show the wide useage of silver in industry, causing demand to drop in case of a price increase.

WTI: Oil is the main driver of the pass-through effect for the EU, especially since Europe depends heavily on oil imports. This causes huge positive impacts on food prices, housing prices, transportation, clothing and education and leads to opposite effects in alcoholic beverages and communications.

NatGas: Natural Gas exhibits interesting opposite price pass-through effects. It has negative impacts on transportation, which fade over time, and also lasting negative effects on food, housing and education, while lasting positive effects on alcoholic beverages, health and communication. The negative effects might be an indication for a run for substitutes, while the positive effects might show the dependency, resp. the complementary character of natural gas on other CPI constituents. 
Cattle: Cattle has a positive pass-through effect on transportation showing up after a year, while having an immediate and lasting positive effect on health and communication. The strong negative impact on cattle are a sign that increase meat prices lead to cheaper education costs.

Cotton: The positive effect of cotton prices on food and education prices are counterbalanced by a negative effect on communication and after a year, also showing up in transportation. The reason why cotton has no effect on clothing might be an indication for a more and more useage of synthetic materials in the clothing and apparel industry.

Wool: Wool even exhibits negative impact on clothing, indicating the rise of substitutes in case of increasing prices.It has long term effects on communication and transportation, even though the short-term drop in transportation costs might also be attributed to substitutes or longer production times.

Coffee: Coffee only shows very weak pass-through effects, indicating that coffee is a very independent commodity. Weak long-term negative effects can be seen in food, education, communications and transport.

Sugar: Sugar exhibits only strong positive effects on transportation and housing, while having a negative impact on prices related to clothing and health.

Some commodity price changes might not have a direct causal effect on a certain CPI constituent, but the VAR considers feedback effects among CPI constituents as well as indirect causal relationships over items and time.

\section{2. $U S$}

For the US, the analysis regarding the commodity price pass-through effect is rather sobering. Due to the high degree of outsourcing, barely any significantly impacting natural resource is being domestically developed and domestically used for production. The pass-through effect for most US CPI constituents is mostly being offset by tolls, taxes or monetary policy, which goes conform with existing research.

Aluminium exhibits no pass-through effect while copper has a positive effect on transport and apparel. Gold has only a negative effect on transportation, maybe for the same reasons as in Europe, where a surge in the gold price indicates an economic slowdown, thus decreasing demand. Interestingly, silver has a positive effect to transportation, showing that silver is widely used in industry and not easy 
to substitute. Oil has a huge positive impact on transportation, while natural gas has only a slight negative effect on communications and apparels.

Cattle, cotton, coffee and sugar show a positive effect on transportation. Wool seems to be the only commodity which exhibits some significant pass-through effects, namely negatively for transportation and apparel. The reason is that the US is still the third largest wool producer (worldatlas.com (2018)), following Australia and China. The reason why increases in wool price have a negative effect on transportation and apparel is once again the substitute effect, since the demand for wool has declined since the mid-1940s with the advent of synthetic fibers.

\section{Conclusion}

This paper analyzes the price pass-through effect of the most heavily traded commodity futures on all EU-CPI and US-CPI constituents. A vast literature has investigated the price-through effect of exchange rate changes but the price-through impact on CPI constituents has rather been under the radar of research so far. Some insights from research suggest that commodity prices explain changes in CPI values, but the explanatory power may get distorted by a diminished role of traditional commodities in domestic production and by offsetting monetary policy actions. Therefore it is important to understand the granular basis by which each aggregated CPI constituent is affected by which commodity price change over time.

Due to globalization, the CPI levels rely increasingly on other factors such as transportation, tolls, monetary policy, etc. than on the underlying commodity. Nevertheless we find explanatory evidence for pass-through effects on the aggregated CPI constituents. Our major finding is that the EU consumer prices are much more sensitive to price changes commodities than US consumer prices. One explanation for the different exposure might be degree of production outsourcing of the EU and US. Since the US has been leading globalization, it appears reasonable that the commodity price pass-through effect is diminished for US consumer prices compared to EU consumer prices.

The second major finding is that transportation is the most affected CPI constituent in the EU as well as the US. Due to the long value added chain of transportation it seems reasonable that this CPI constituent reacts most to changes in commodity prices.

In short, the results indicate interesting differences in the commodity price passthrough effects between EU and US economic structure, consumer behavior and production structure, caused by the high degree of deindustrialization of the US compared to the exposure of European vale added chains on commodity price fluctuations. 


\section{Declaration}

- Availability of data and materials: Data source: Bloomberg. The datasets used and/or analysed during the current study are available from the corresponding author on reasonable request.

- Competing interests: The authors declare that they have no competing interests" in this section.

- Funding: "Not applicable"

- Authors' contributions: SU was setting up the research idea, downloading the data, and writing the text. GC was programming and helped interpreting the data and with some formulations in the text.

- Acknowledgements: "Not applicable"

- Authors' information (optional):Gökhan Cebiroğlu:Credit Suisse, 1 Cabot Square, Canary Wharf, London E14 4QJ, UK, email: goekhan.cebi@gmail.com, and Stephan Unger:Saint Anselm College, Department of Economics \& Business, Saint Anselm Drive 100, Manchester, NH, USA, email: sunger@anselm.edu. 


\section{References}

Blomberg S. Brock, and Harris Ethan S., (1995) The Commodity-Consumer Price Connection: Fact or Fable? Economic Policy Review. 1:3. https://ssrn.com/abstract=1028825. Accessed 23 Dec 2019.

Bureau of Labor Statistics (2013) Frequently Asked Questions about the Chained Consumer Price Index for All Urban Consumers (C-CPI-U), Consumer Price Index, Retrieved April 11, 2013.

Campa JM, and Goldberg LS (2005) Exchange Rate Pass-Through into Import Prices. The Review of Economics and Statistics 2005. 87: 679-690.

Engel Charles, 2013, Inflation and globalisation: a modelling perspective Springer, BIS Papers (70). University of Wisconsin and NBER.

Engle $\mathrm{R}(2001)$ The use of $A R C H / G A R C H$ models in applied econometrics, The Journal of Economic Perspectives. 15(4):157-168.

Feinberg Robert M (1986) The Interaction of Foreign Exchange and Market Power Effects on German Domestic Prices, Journal of Industrial Economics. 35:61-70.

Feinberg, Robert M., 1989, The Effects of Foreign Exchange Movements on U.S. Domestic Prices, Review of Economics and Statistics, 1989, Vol. 71, pp. 505-11.

Kohn Donald L., June 16, 2006, The Effects of Globalization on Inflation and Their Implications for Monetary Policy, At the Federal Reserve Bank of Boston's 51st Economic Conference, Chatham, Massachusetts, https://www.federalreserve.gov/newsevents/speech/kohn20060616a.htm. Accessed 23 Dec 2019.

Lütkepohl H., 2006, New Introduction to Multiple Time Series Analysis, Springer.

Marazzi, M., Sheets, N., Vigfusson, R., Faust J., Gagnon, J., Marquez, J., Martin, R., Reeve, T., and Rogers, J., 2005, Exchange Rate Pass-through to U.S. Import Prices: Some New Evidence, Board of Governors of the Federal Reserve System, International Finance Discussion Papers, Number 833.

McCarthy, J., October 2007, Pass-Through of Exchange Rates and Import Prices to Domestic Inflation in Some Industrialized Economies, Eastern Econ Journal. 33(4): 511-537, https://doi.org/10.1057/eej.2007.38. Accessed 23 Dec 2019.

Papademos Lucas, 2007, The effects of globalisation on inflation, liquidity and monetary policy, Speech at the conference on the "International Dimensions of Monetary Policy" organised by the National Bureau of Economic Research. S'Agaro, Girona, 11 June 2007, URL: https : 


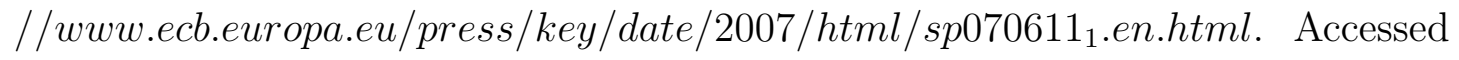
23 Dec 2019.

Parsley D, Popper H (1998) Exchange Rates. Domestic Prices, and Central Bank Actions: Recent U.S. Experience, Southern Economic Journal. 64(4): 957-972.

Rigobon R (2008) Commodities Pass Through To CPI Item Prices, MIT and NBE. http://siteresources.worldbank.org/EXTLACOFFICEOFCE/Resources/8708921253047679843/Rigobon2009.pdf. Accessed: 23 Dec 2019.

Woo Wing T (1984), Exchange Rates and the Prices of Nonfood, Nonfuel Products, Brookings Papers on Economic Activity. 2:511-530.

Worldatlas.com (2018) The World's Top Wool Producing Countries. https://www.worldatlas.com/articles/the-world-s-top-wool-producingcountries.html. Accessed 23 Dec 2019. 

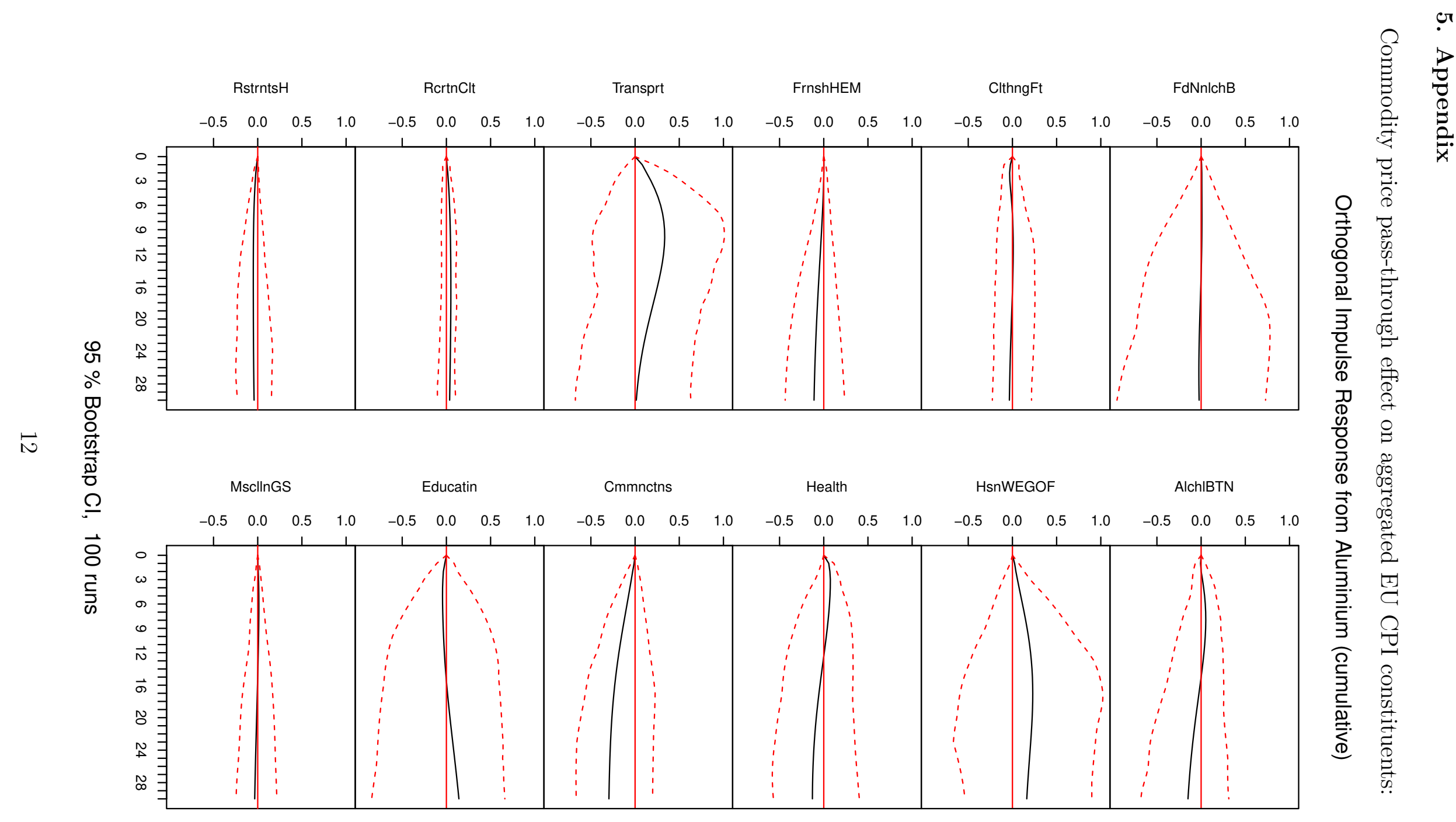


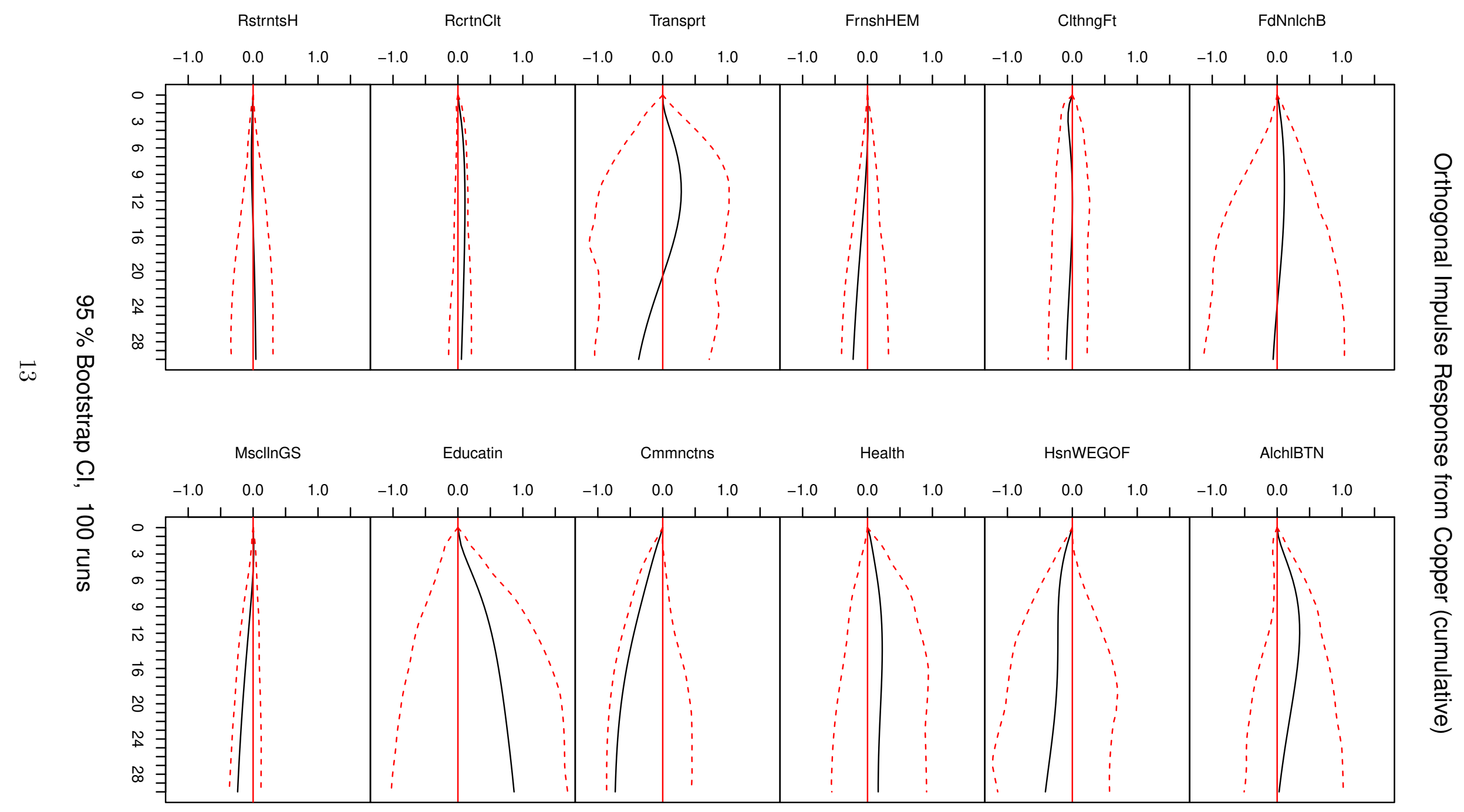




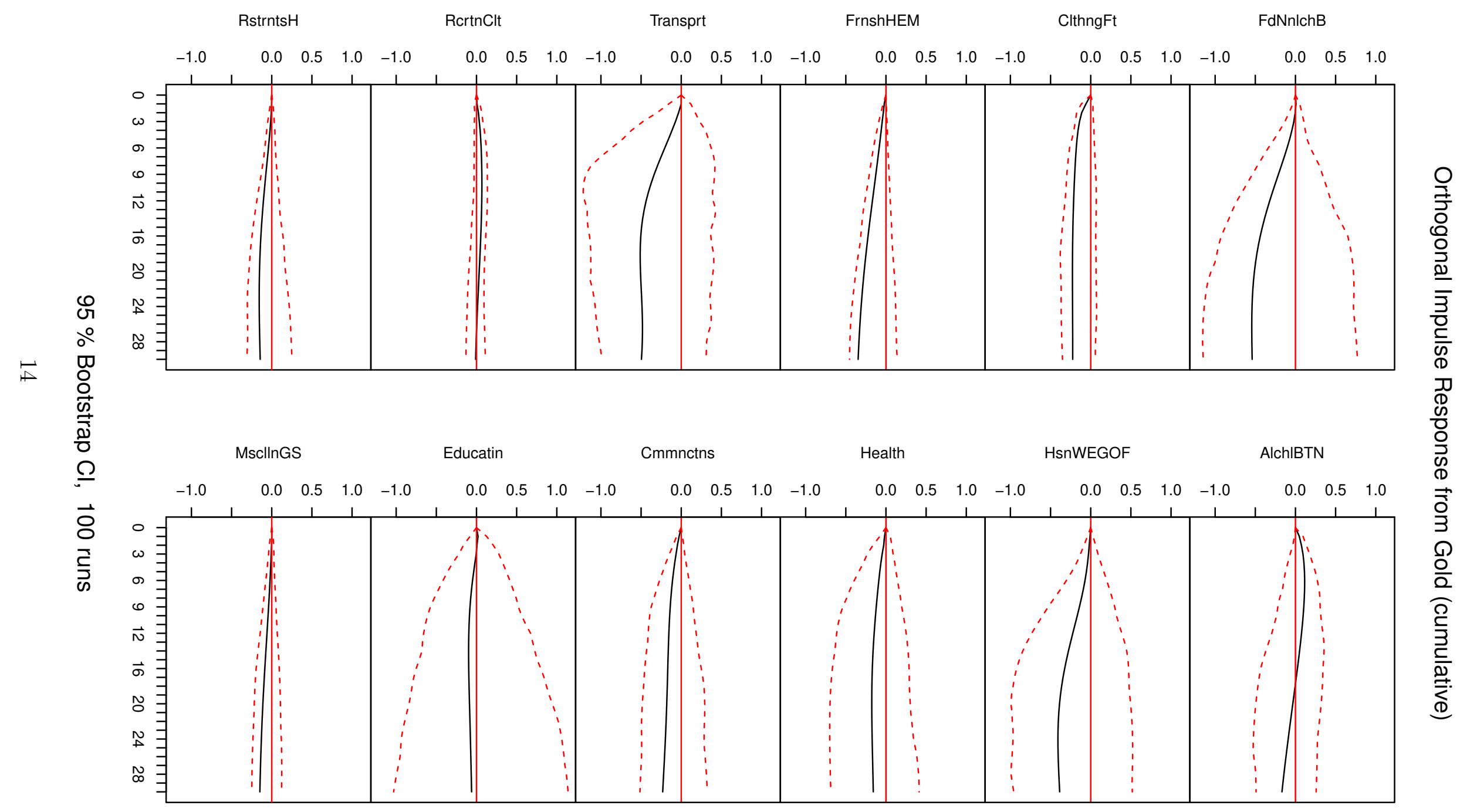




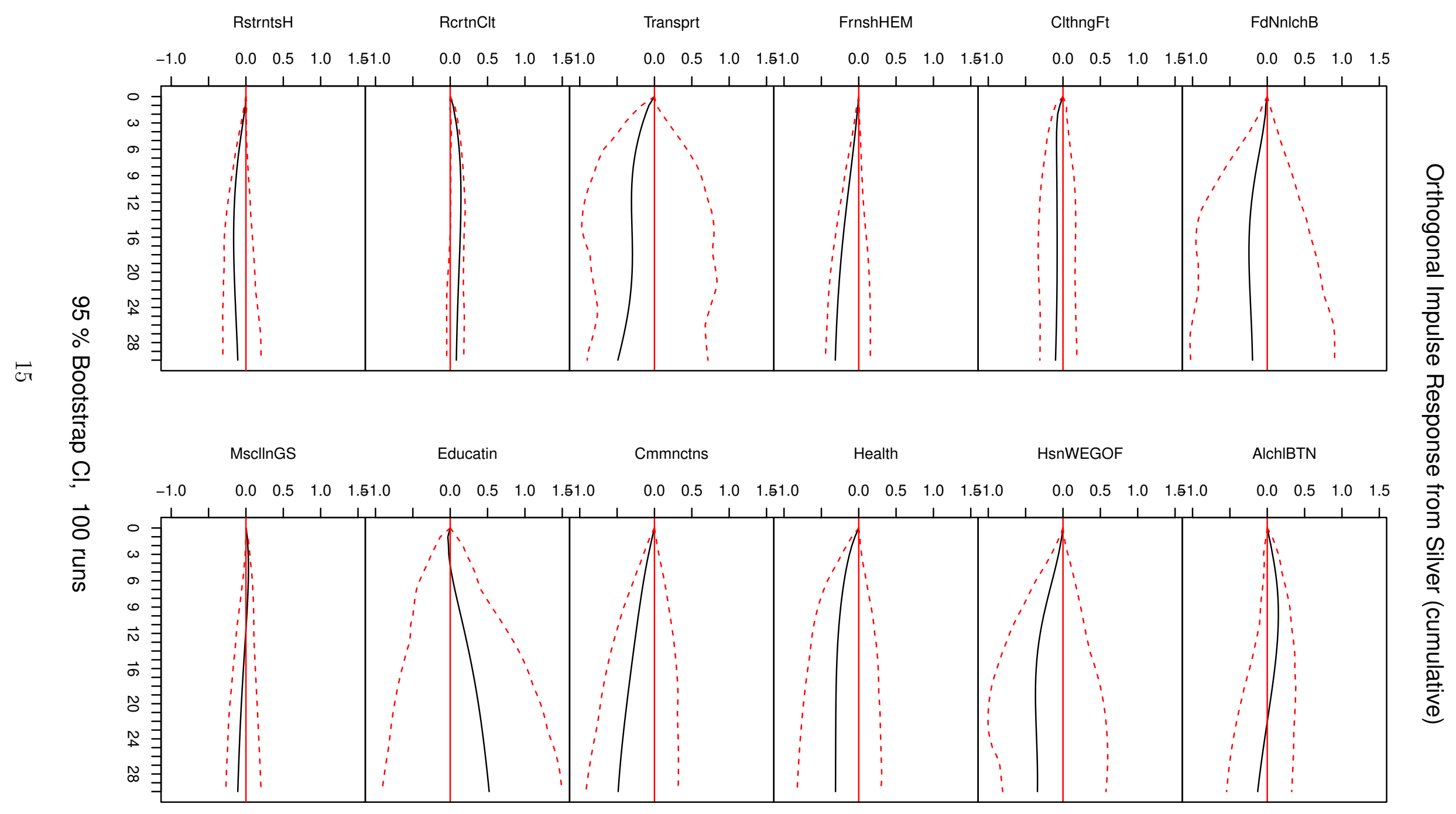


Orthogonal Impulse Response from WTI (cumulative)
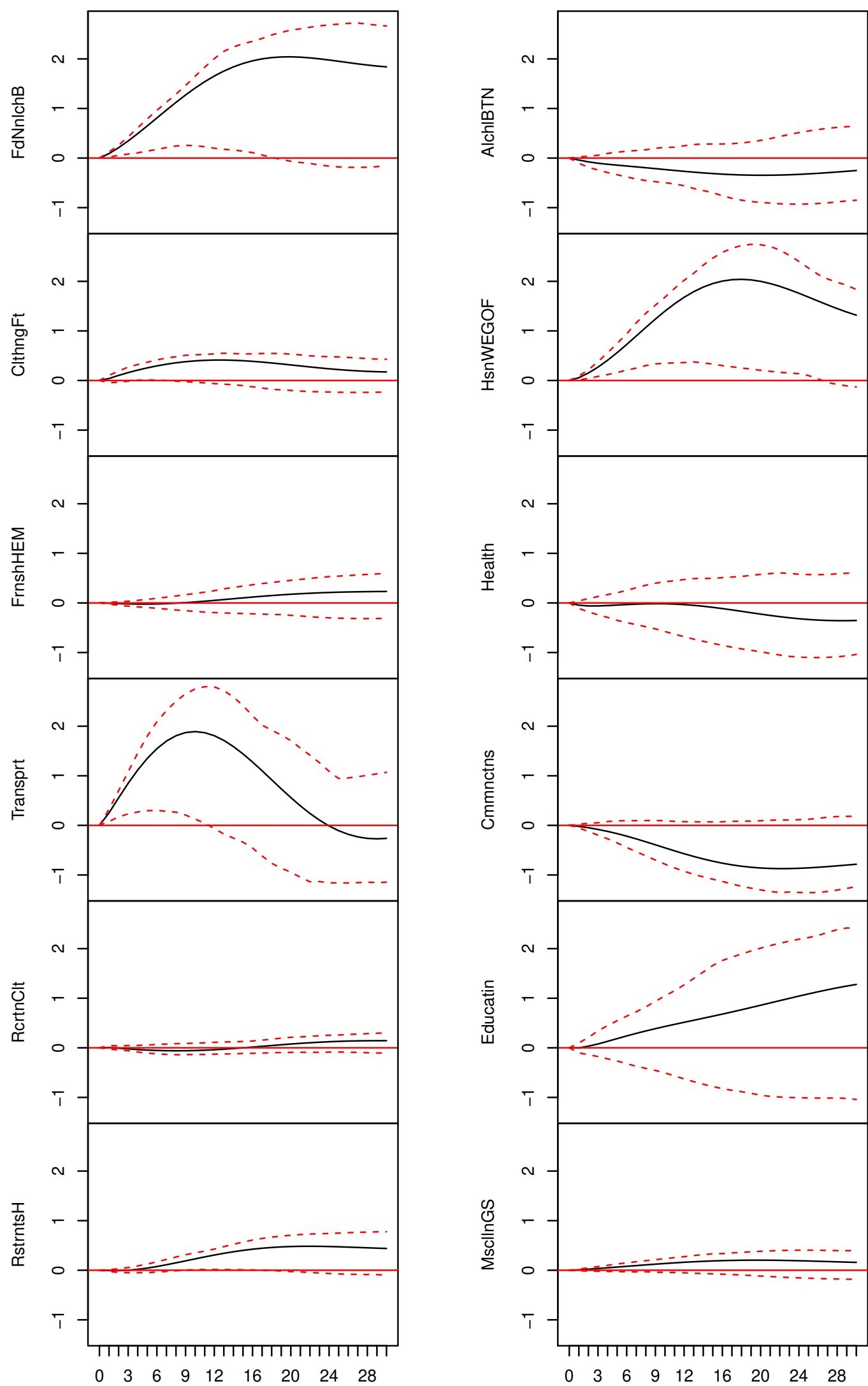

95 \% Bootstrap Cl, 100 runs 


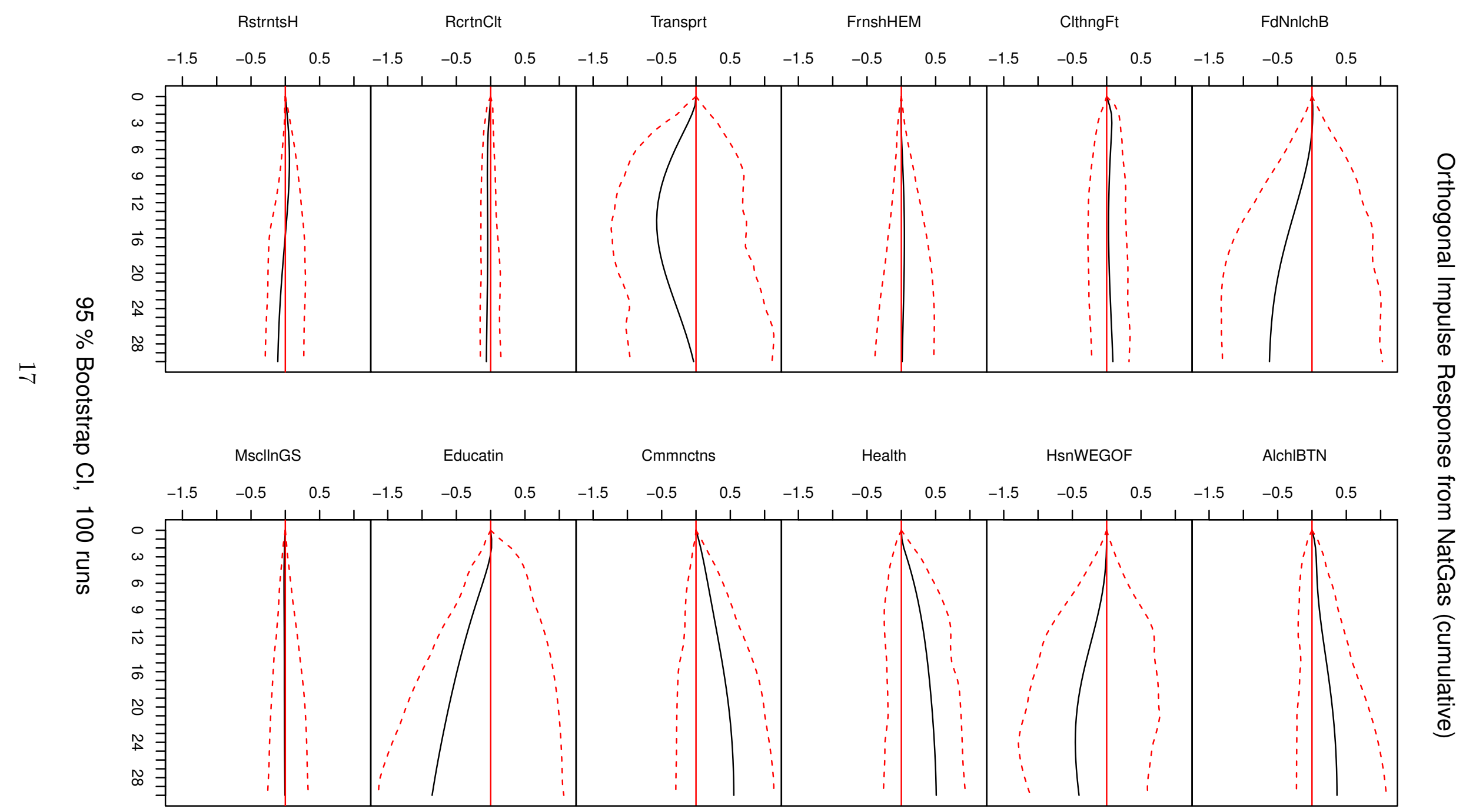




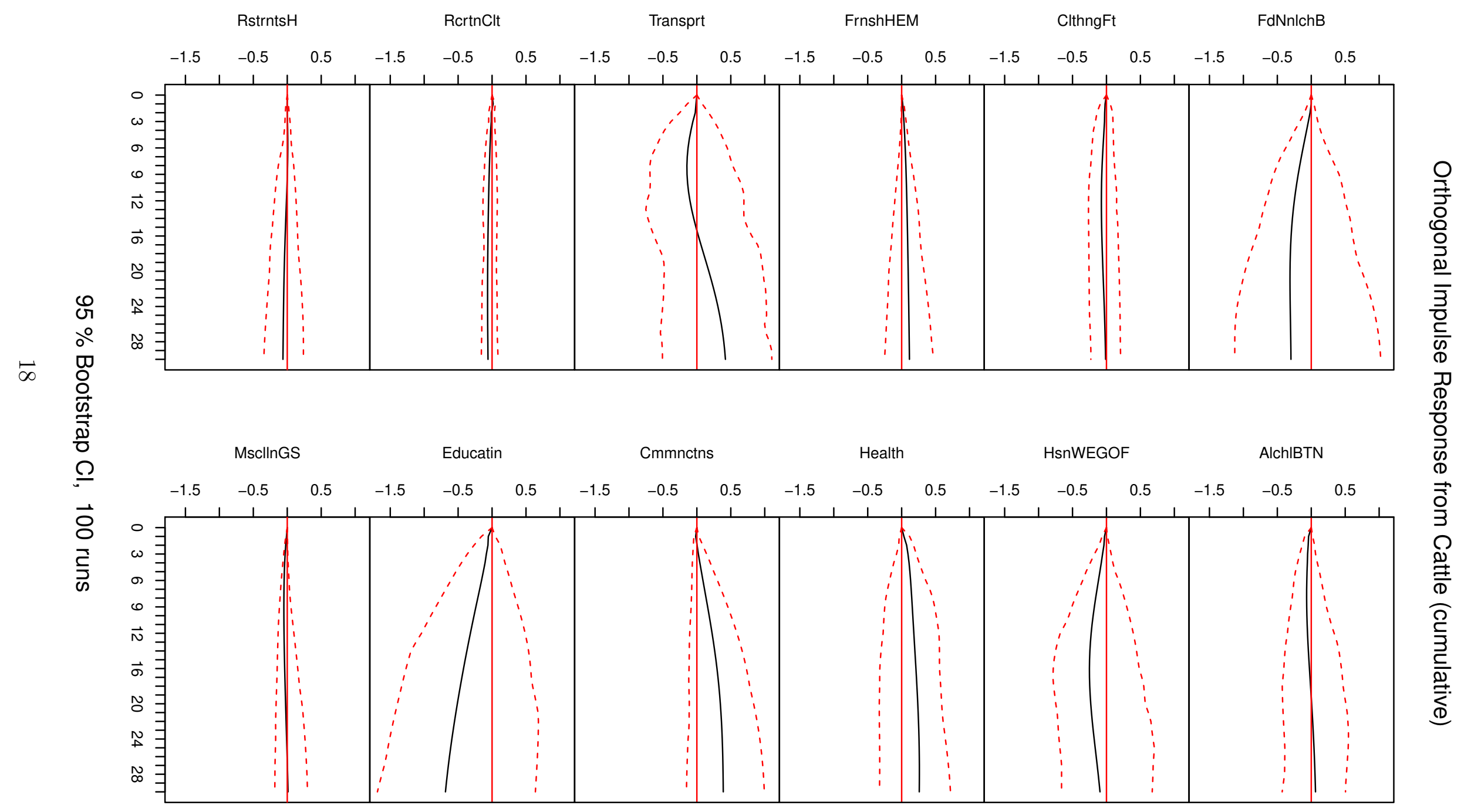




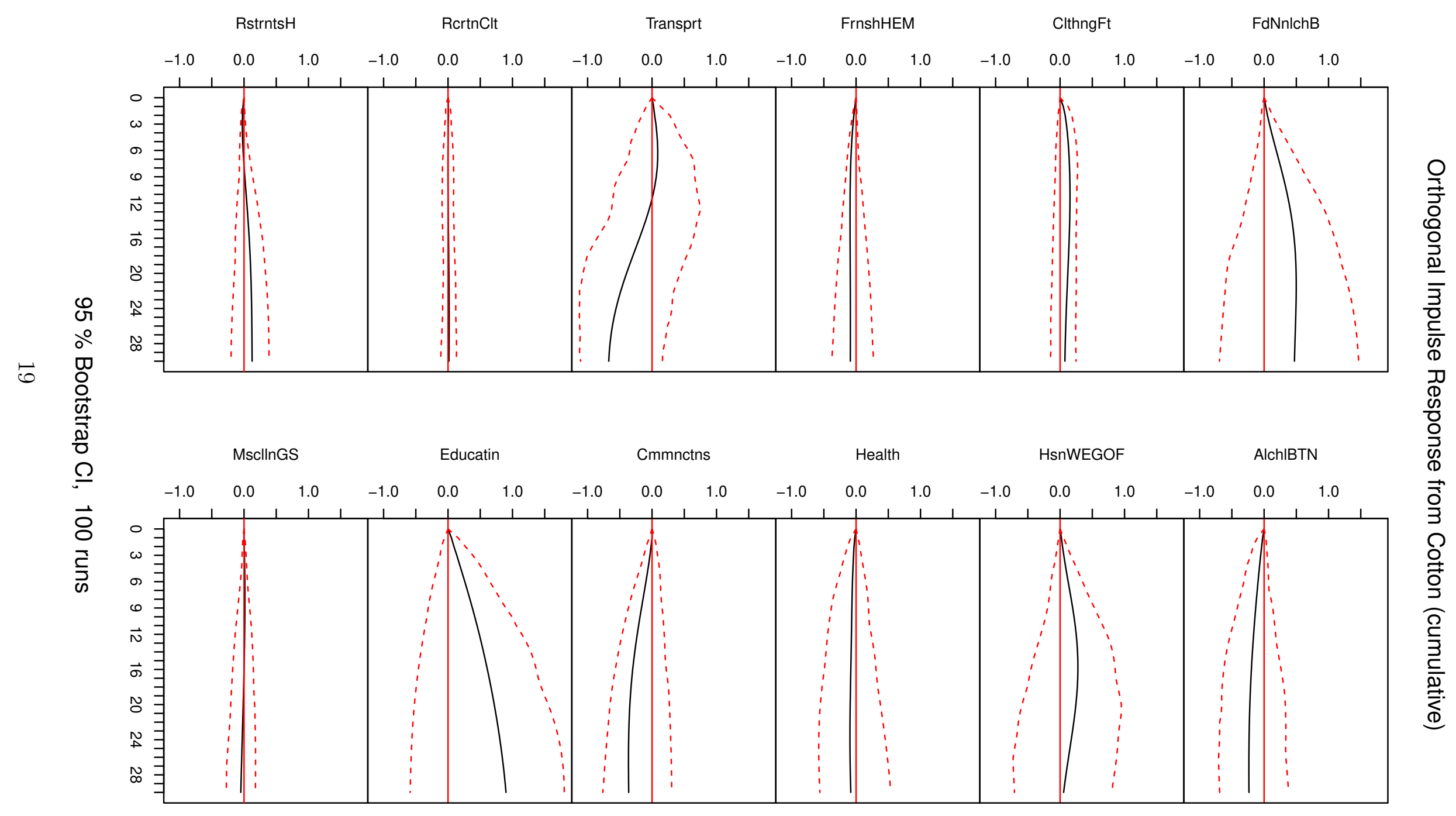




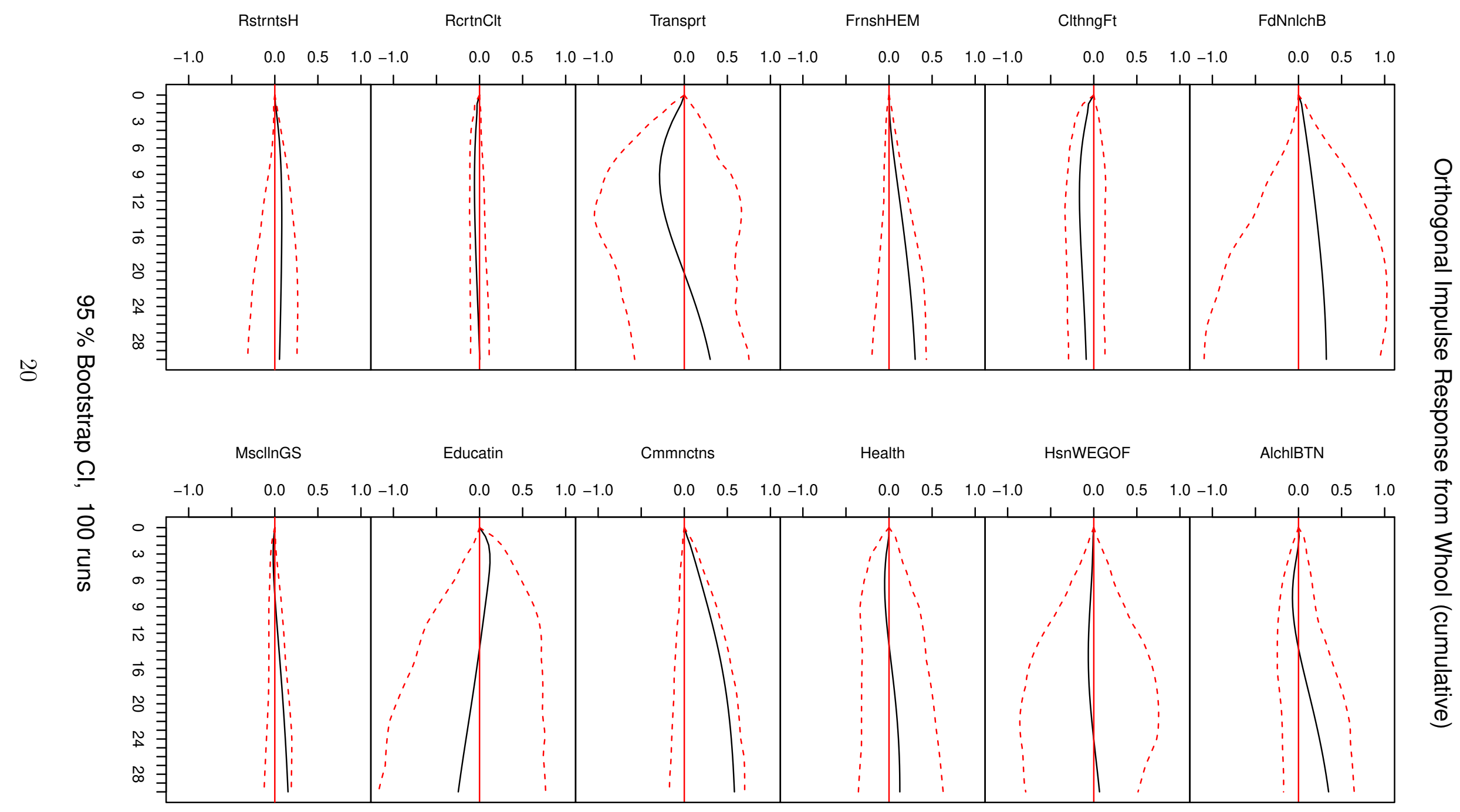




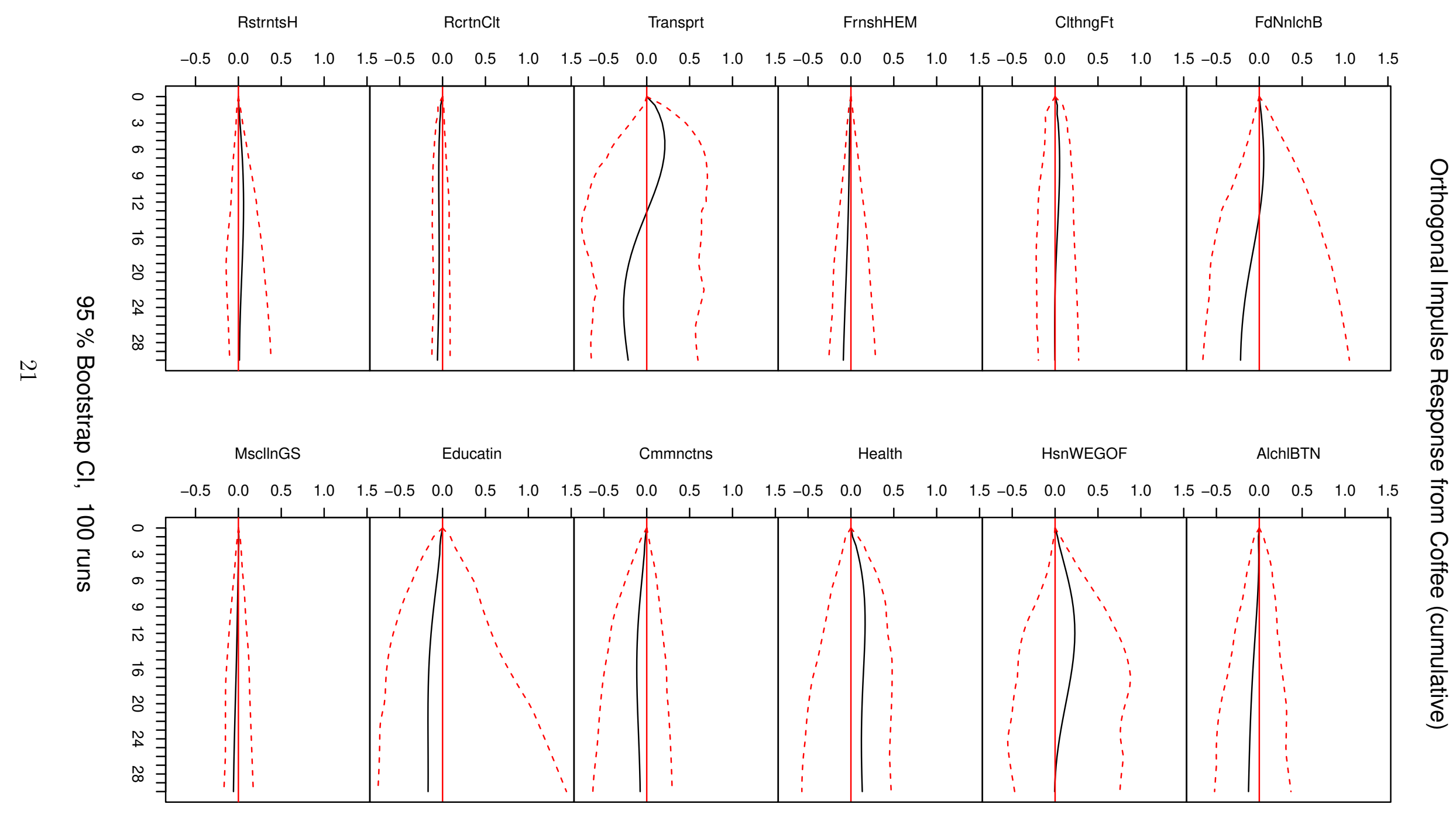




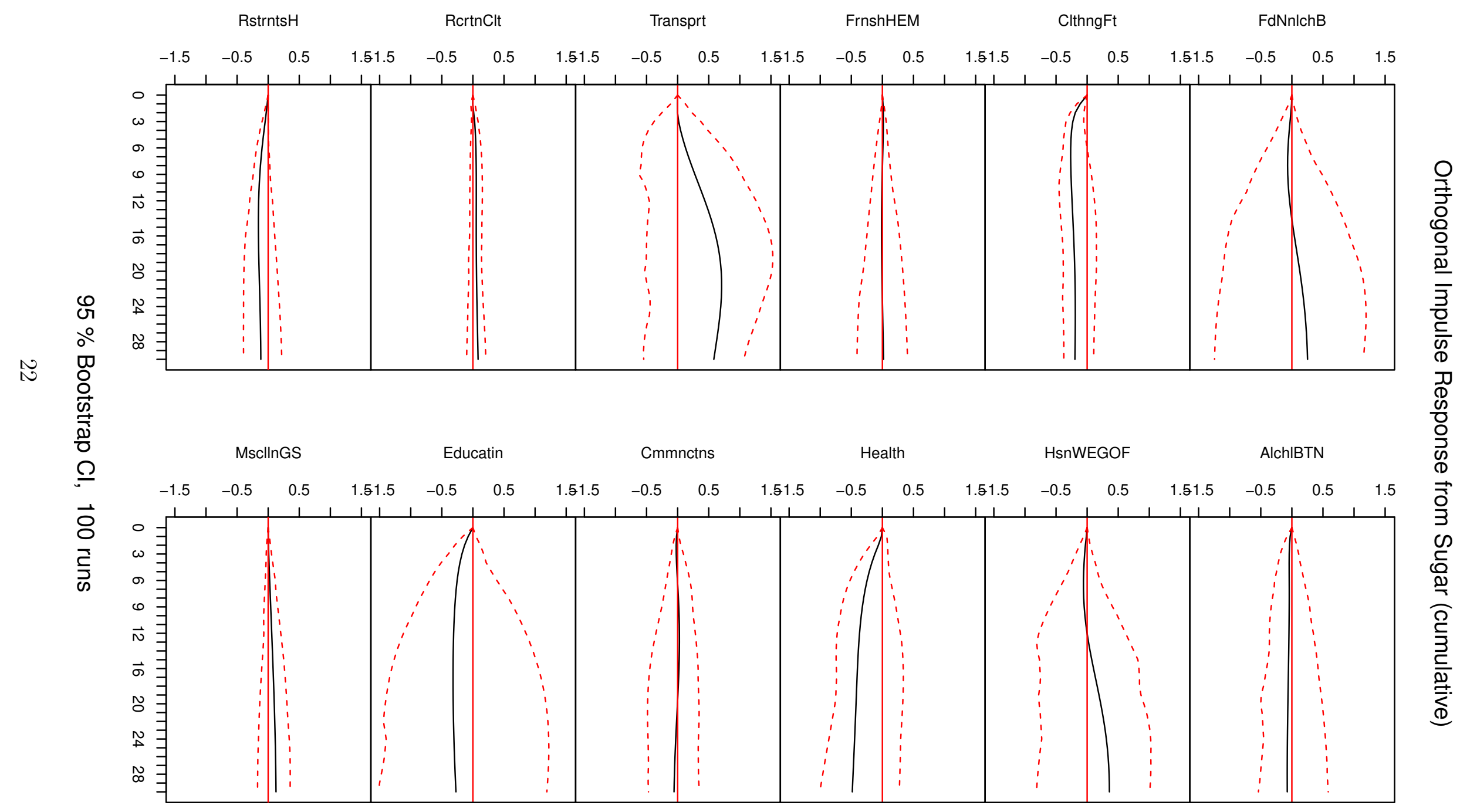




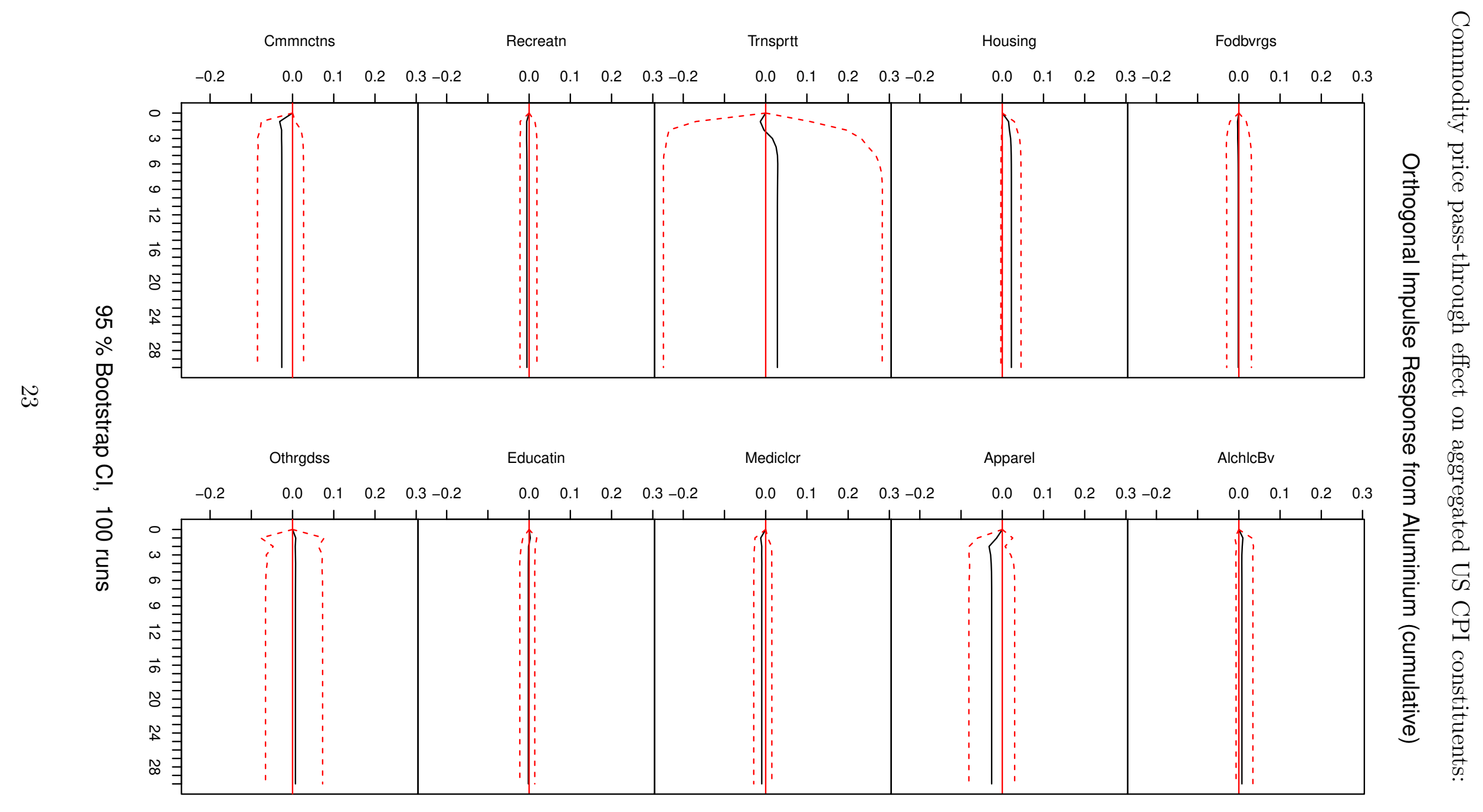




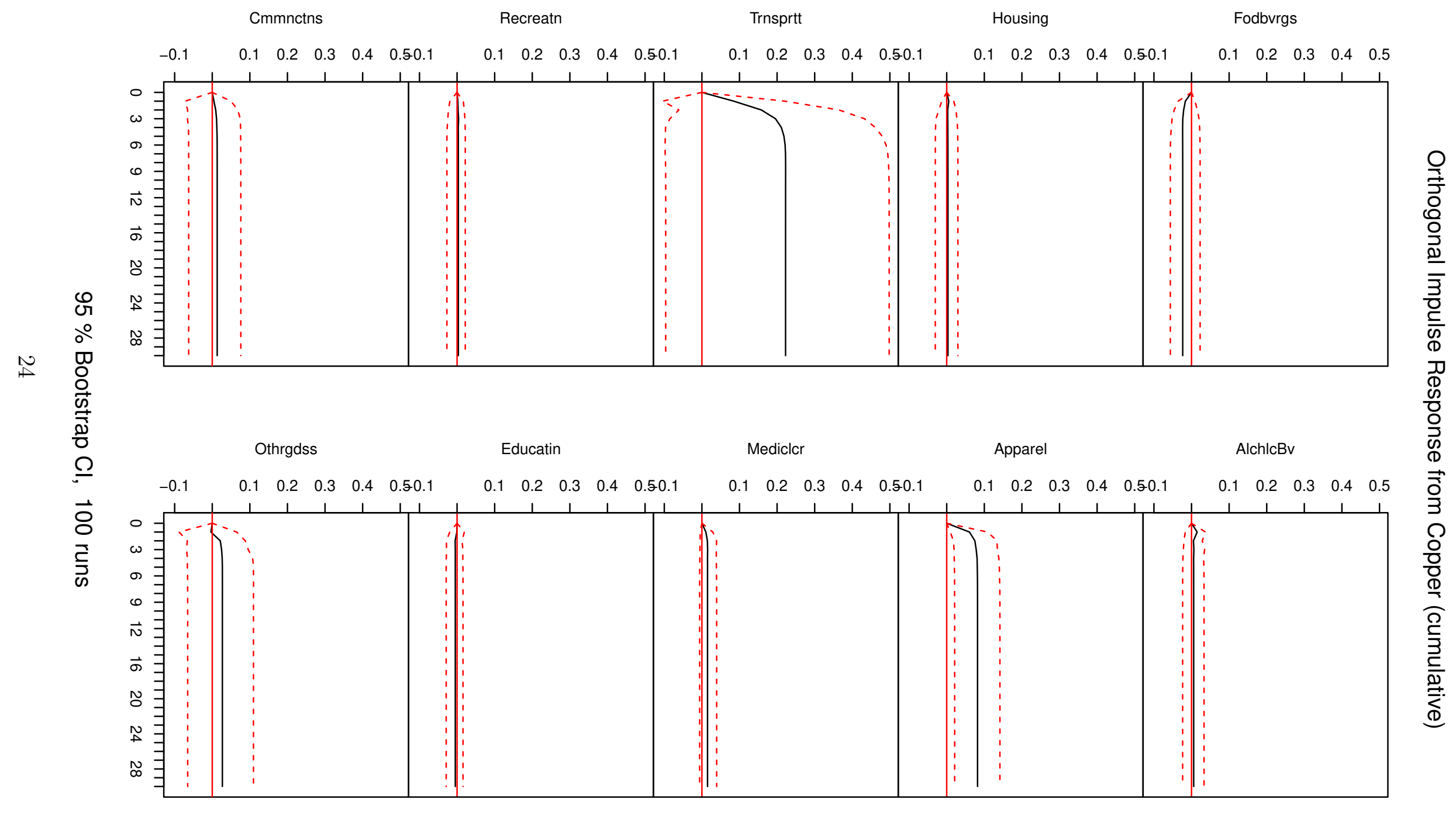




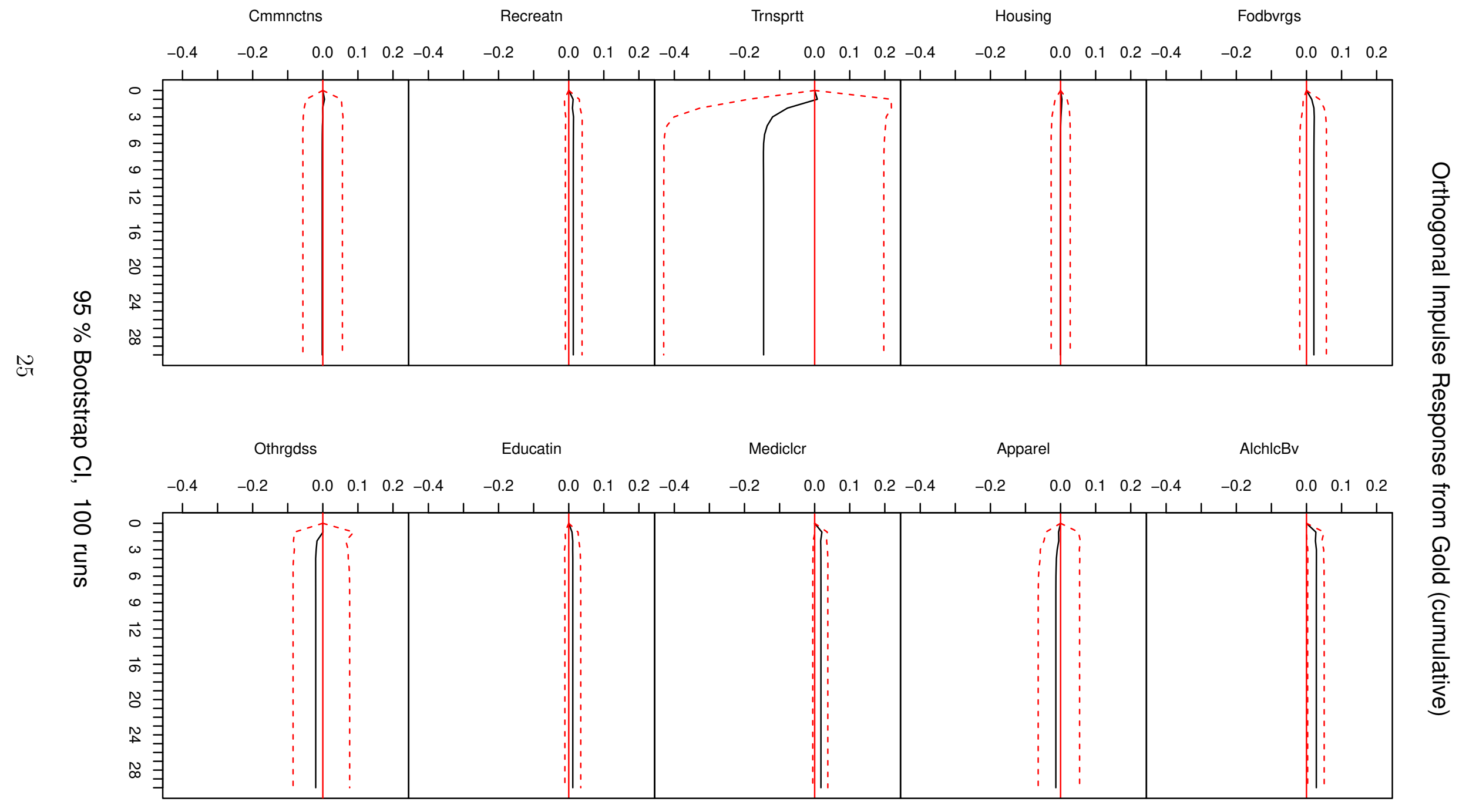




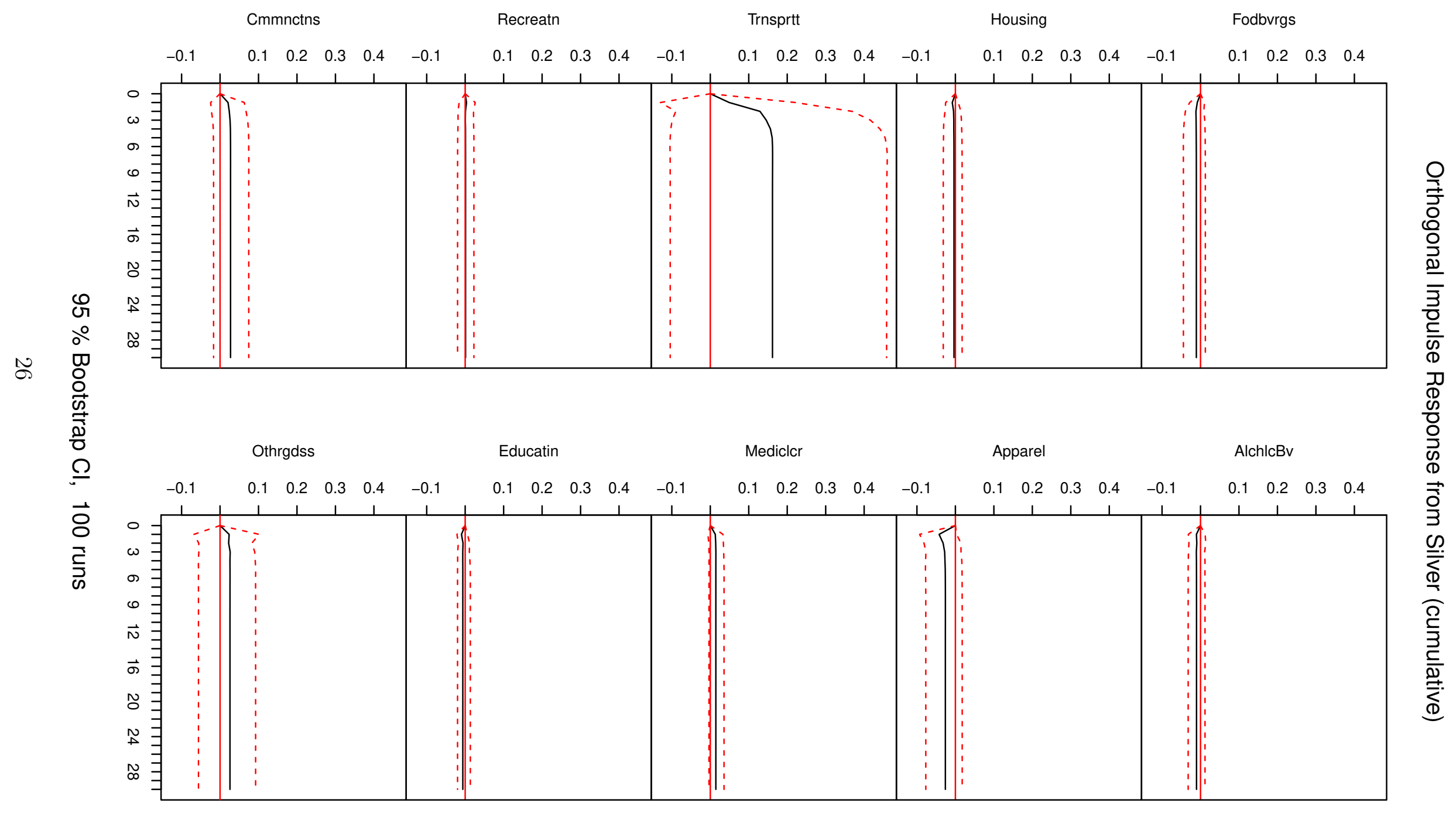




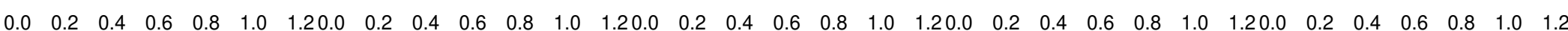

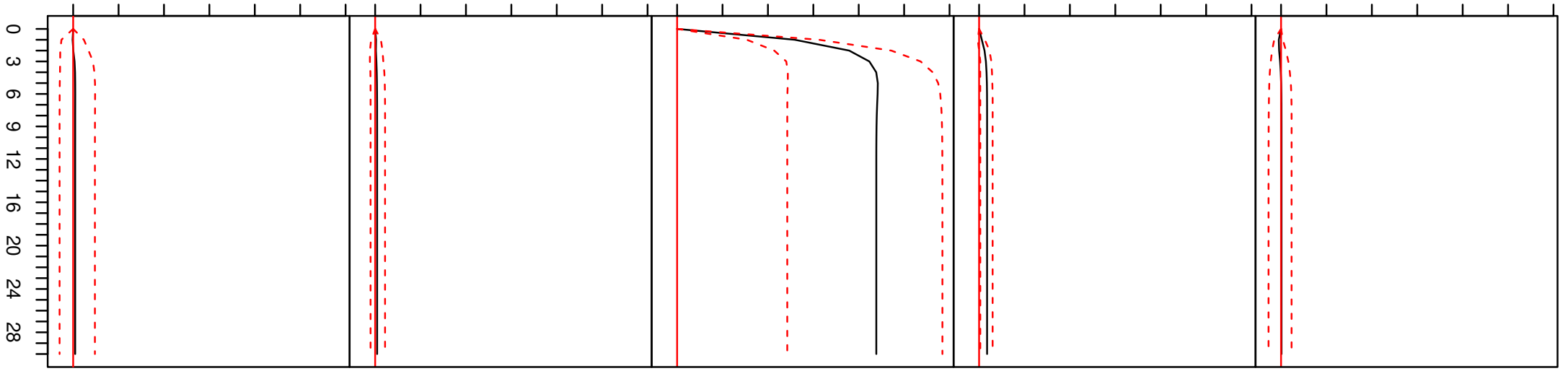

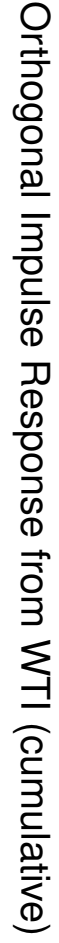

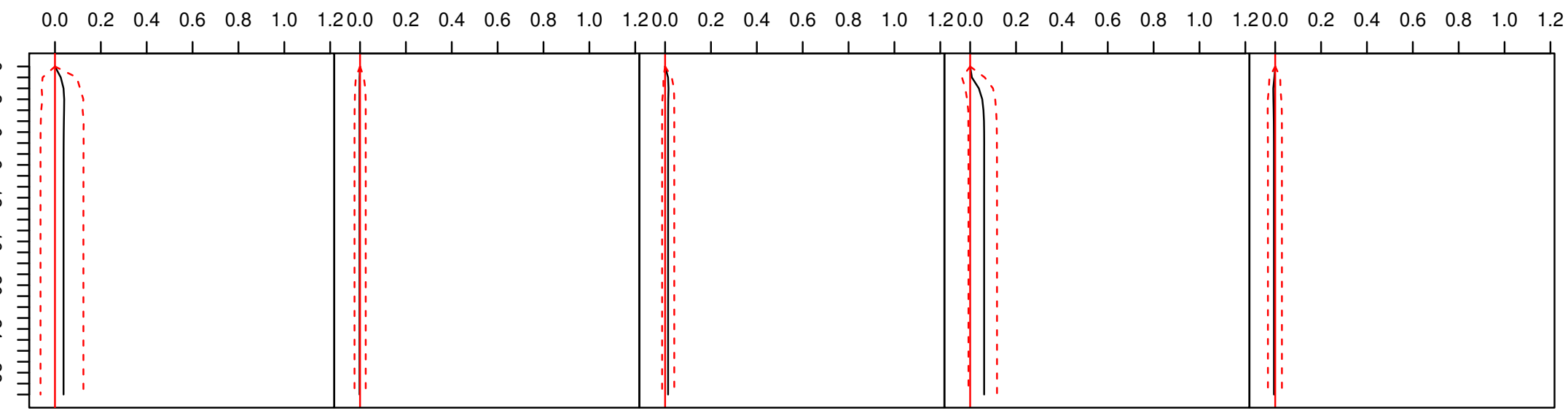




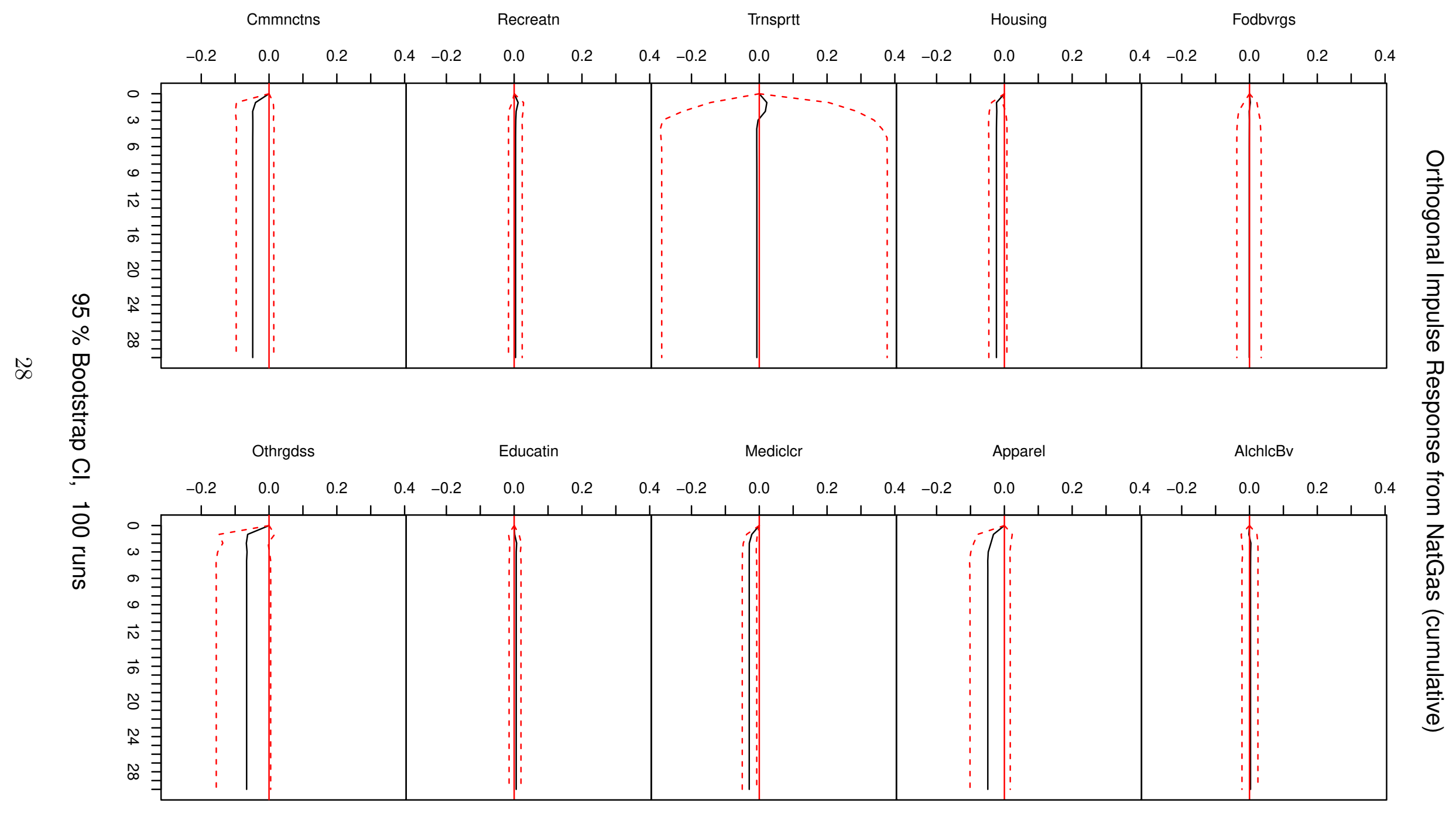




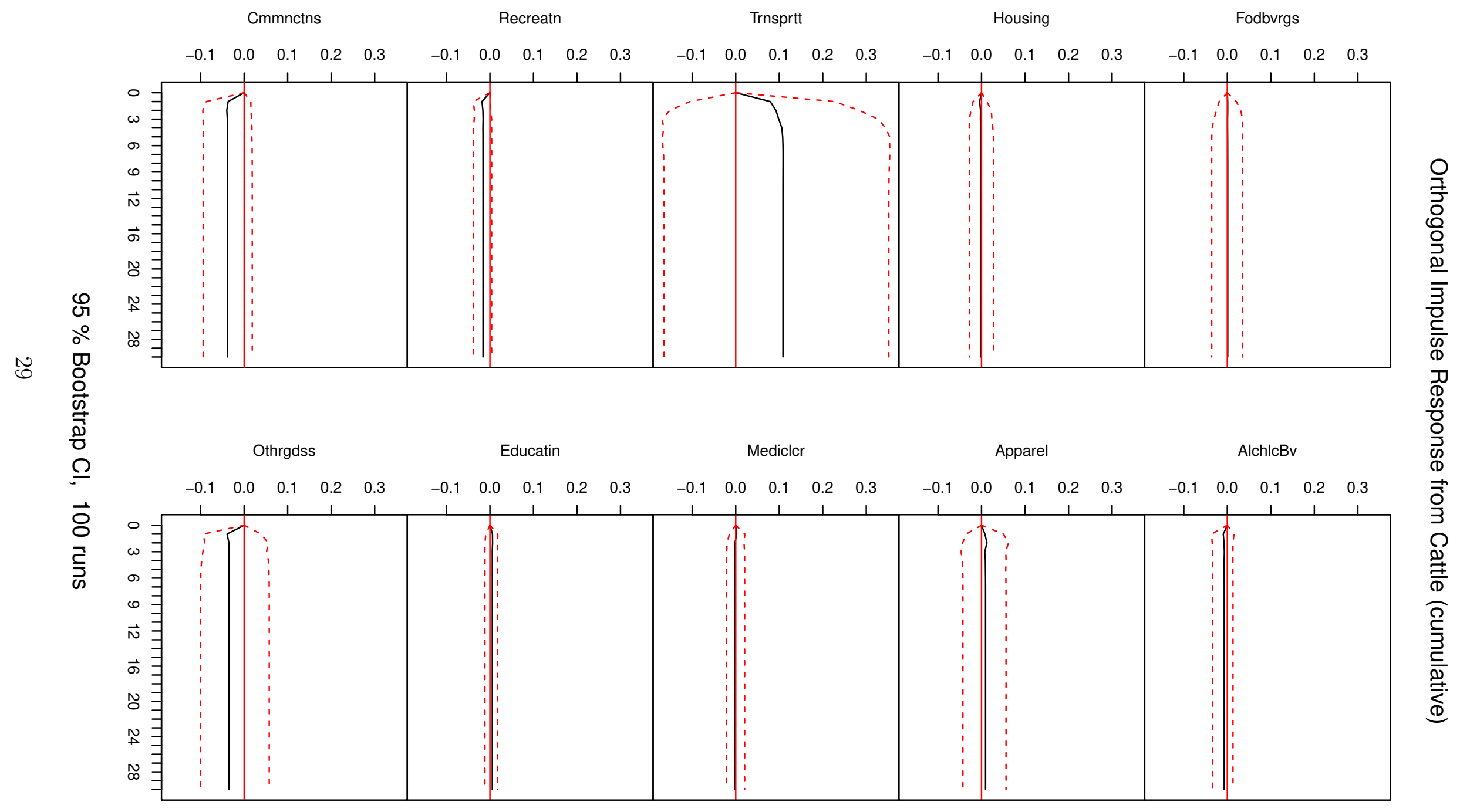




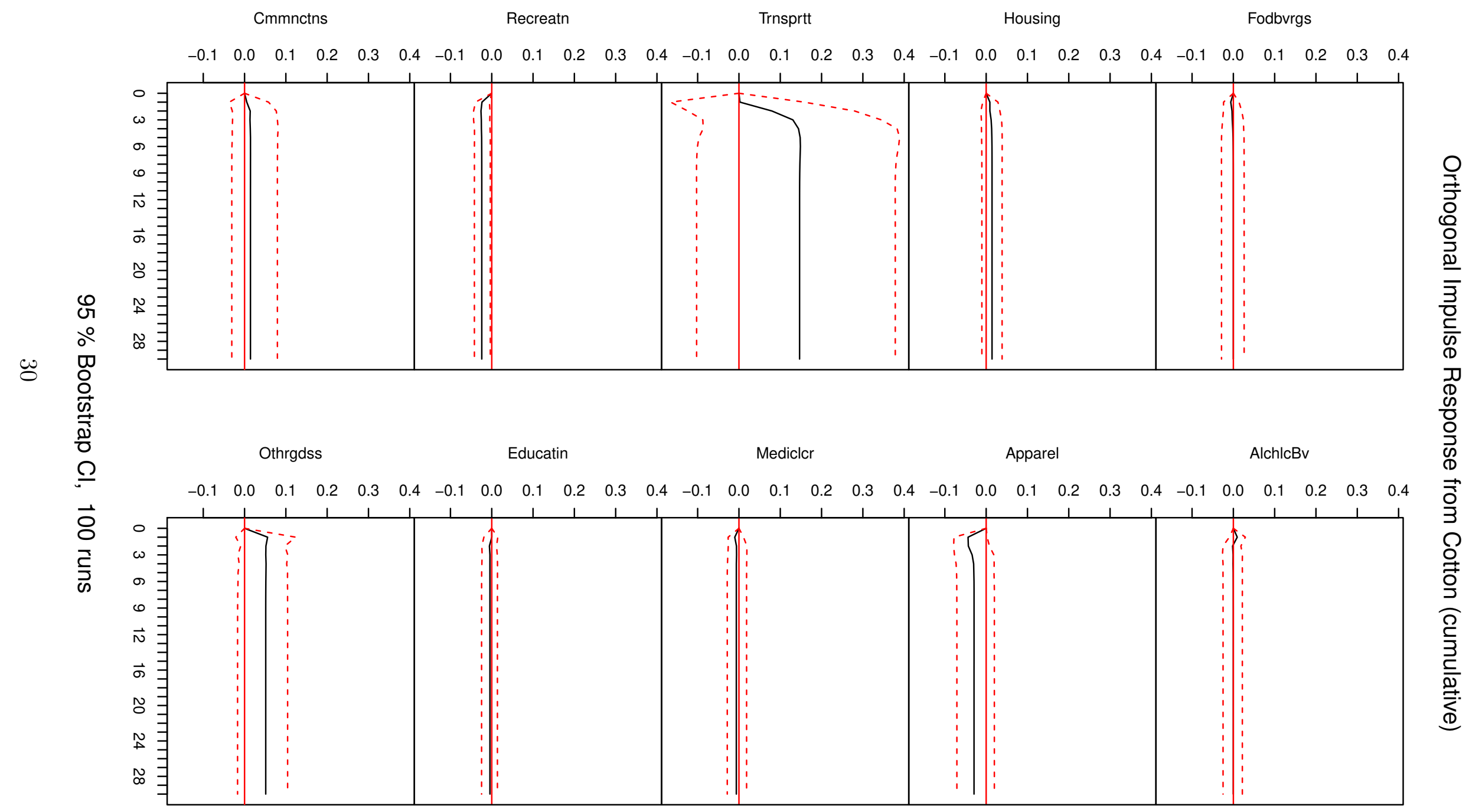




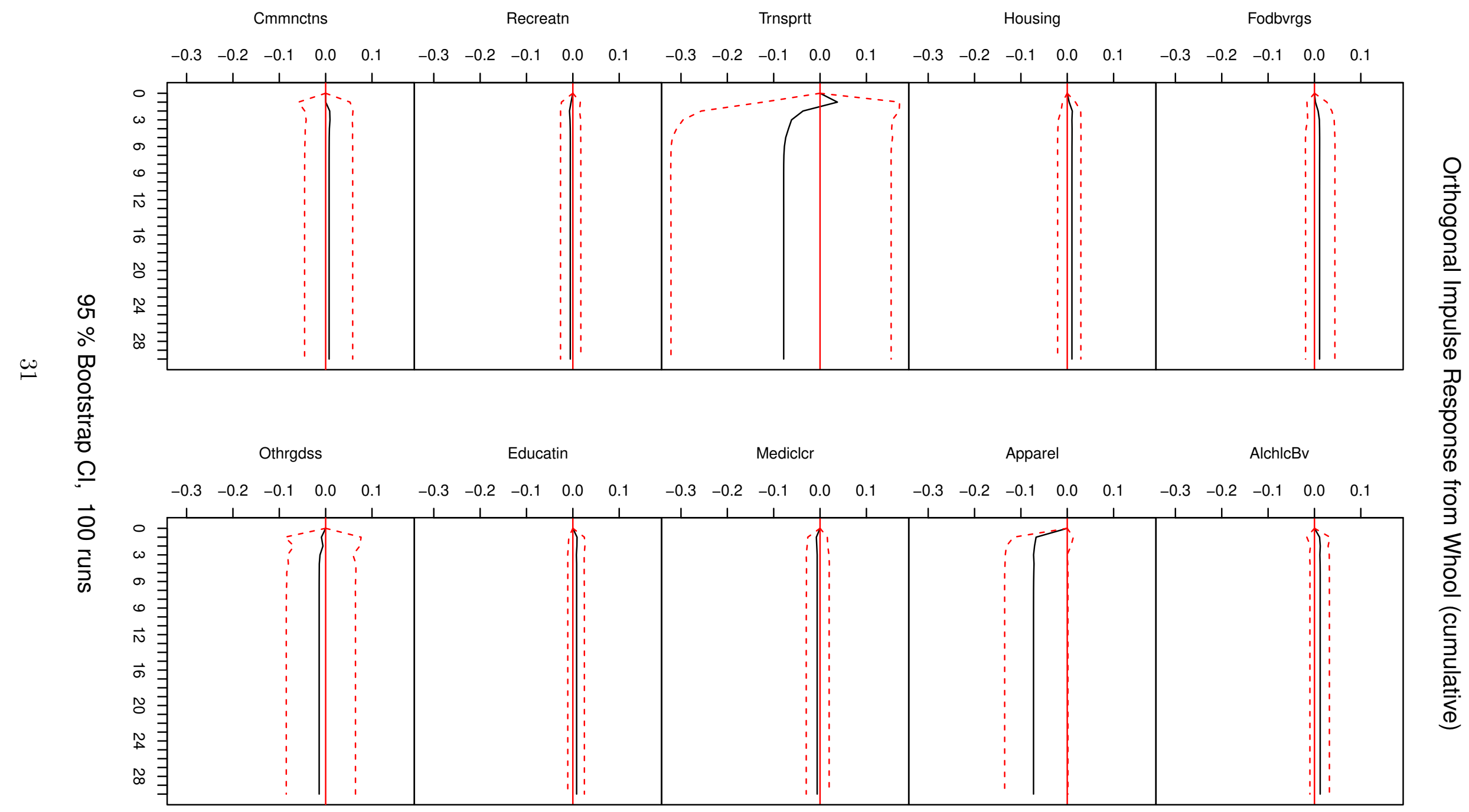




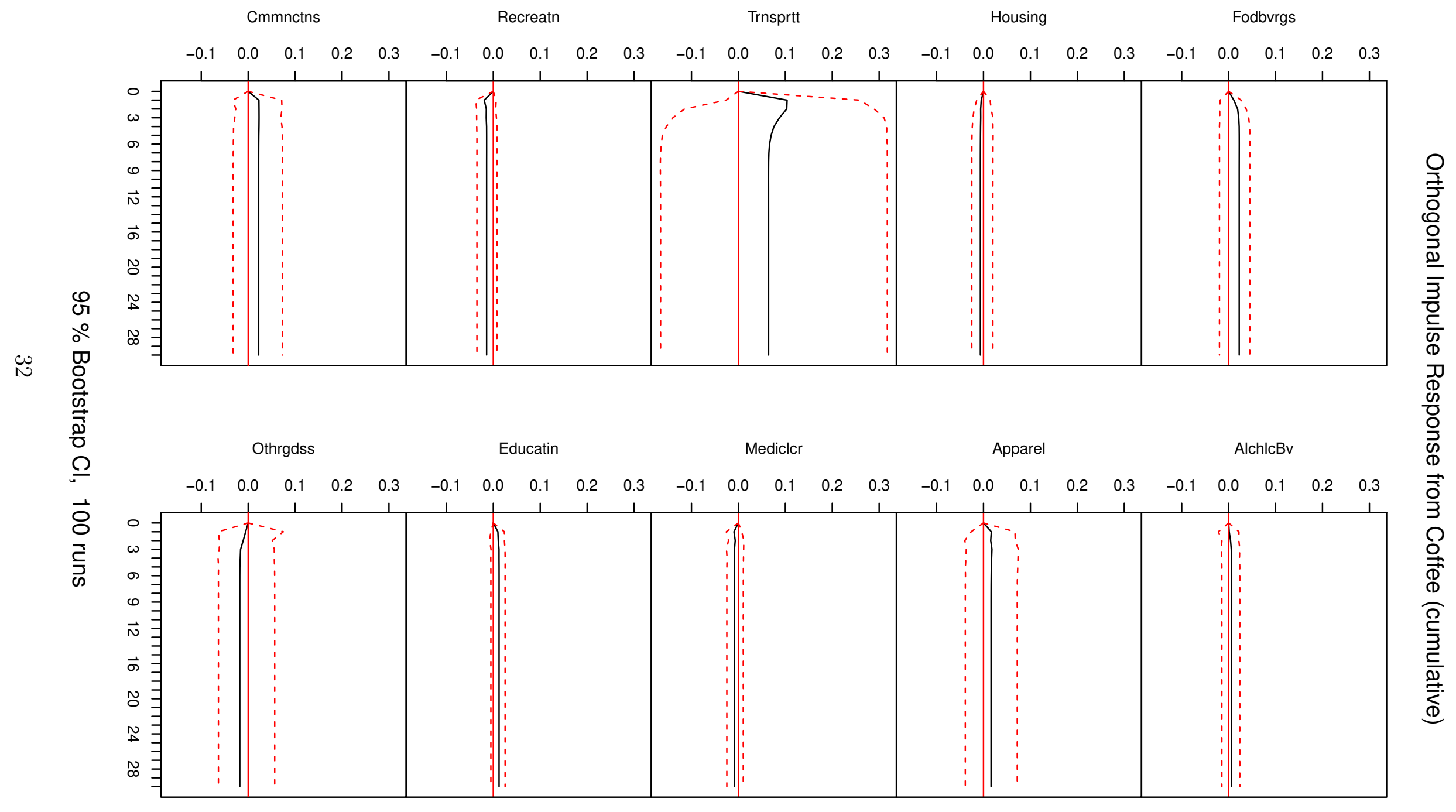




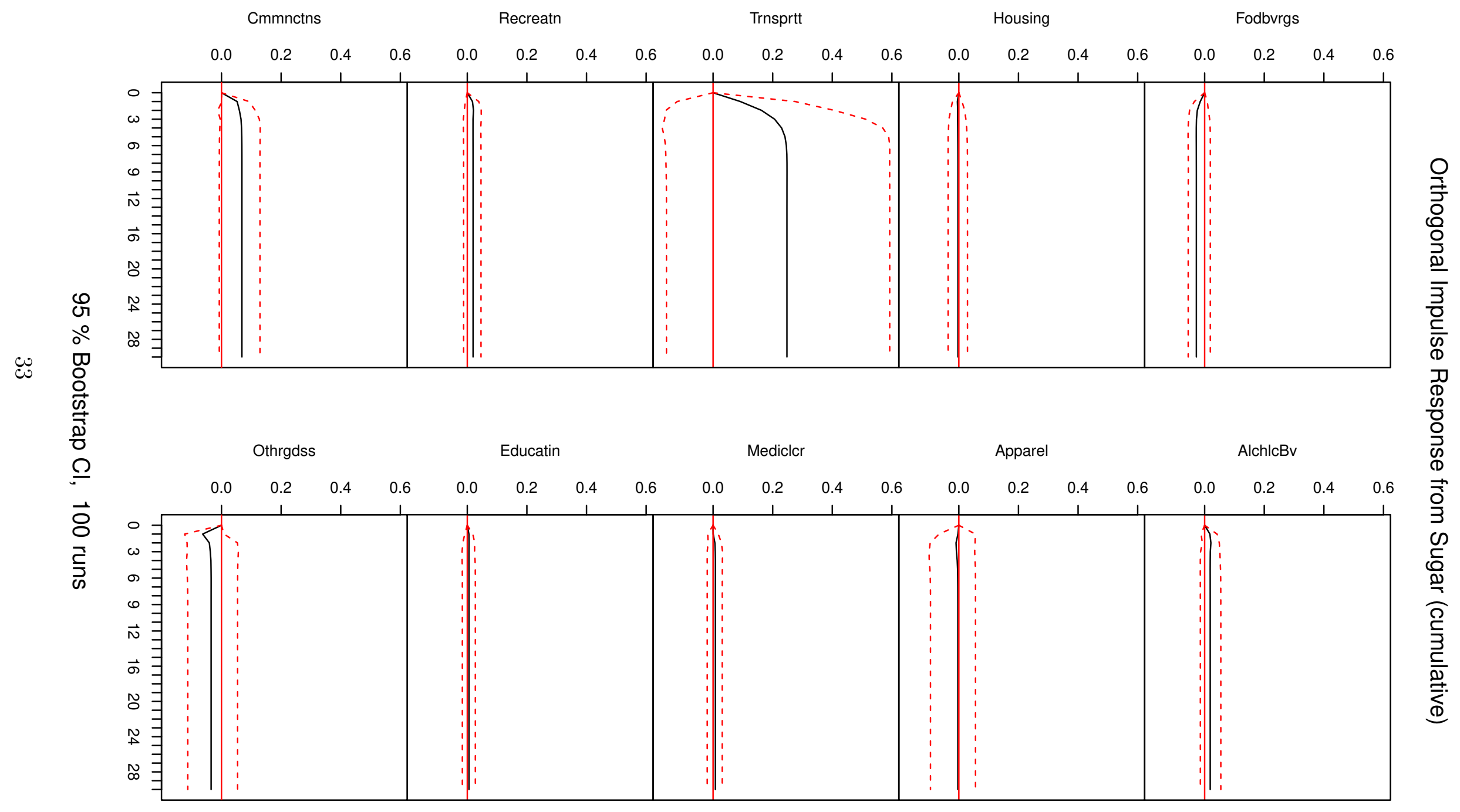

